\title{
SENSITIVITY ANALYSIS OF CERES-WHEAT MODEL TO VARIOUS WEATHER AND NON-WEATHER PARAMETERS FOR WHEAT (CV.GW-496)
}

\author{
H.R. Patel ${ }^{1}$ and A.M.Shekh ${ }^{1}$
}

\begin{abstract}
The CERES-wheat model was calibrated and validated based on actual data of field experiments with an objective to test the sensitivity of model to various weather and nonweather parameters for wheat $(G W-496)$ in middle Gujrat Agro-climatic region, Anand (Gujarat, India). The results showed that grain yields as simulated by the CERES-wheat (cv. GW-496) model due to alteration of ambient temperature in incremental units showed a gradual decrease in yield, while the down scaled ambient temperature was observed to have increased the yield by 2 and $6 \%$ at 4 and $5{ }^{\circ} \mathrm{C}$ reduction in temperature respectively. The percentage values of change in the yield were 2 and 8 at -1 and $-5{ }^{\circ} \mathrm{C}$ over the base yield respectively in case of down scaled ambient temperature under suboptimal conditions. Increase in daily solar radiation (3 to $\left.5 \mathrm{MJm}^{-2}\right)$, resulted into nearly 6 to $9 \%$ increase in yield over the base yield. Under gradual decrease of solar radiation no yield increment over the base yield was observed. This showed that the model was less sensitive to solar radiation than it was to temperature. When carbon dioxide $\left(\mathrm{CO}_{2}\right)$ concentration was doubled, the grain yield increased up to $43 \%$ over the base yield in optimal conditions, while corresponding yield increment under sub-optimal conditions was 73\%. This showed that the model used had the potential for assessing impact of climate change on wheat production. Large yield reductions were noted under increasing plant population (150 to $500 \mathrm{sq}$. per mts) both in optimal and sub-optimal conditions. This provided strong evidence in respect of the robustness of the model to account for the effects of plant population.
\end{abstract}

Key words: Sensitivity analysis, CERES-wheat, simulation, optimal and sub-optimal situations

\section{INTRODUCTION}

A major issue with simulation modeling is the large number of model parameters (calibration values) and input data that are required. The question naturally arises: what happens if we get some of these wrong? The correct question is: how sensitive is the model to variations in parameters or data? Especially since parameter calibration is largely a black art, sensitivity analysis allows us to see where we should concentrate our calibration and modeling efforts, i.e., where the model is most sensitive.
Sensitivity means rate of change in output variable per unit change in input variable or parameter Pathak et al. (2003) studied trends of climatic potential yields and on-farm yields of Wheat and rice in the Indo-Gangetic Plains using the DSSAT model. (CERES-Wheat and CERES-Rice). This showed that solar radiation decrease by $1.7 \mathrm{MJm}^{-2}$ day $^{-1}$ reduced rice and wheat yields from 10.9 to 10.3 and 8.3 to 7.5 $\mathrm{Mg} \mathrm{ha}^{-1}$,respectively.Increased minimum temperature by $1.7^{\circ} \mathrm{C}$ decreased yields of

${ }^{1}$ Dept. of Agri. Meteorology, B.A.College of Agriculture, Anand Agricultural University, Anand-300 110,Gujarat, 21 India. 
rice and wheat from 10.9 to 10.0 and 8.3 to $8.1 \mathrm{Mg} \mathrm{ha}^{-1}$, respectively. Dhaliwal et al. (1997) tested the sensitivity of CERES-Wheat model for wheat cv. HD2329. The results of sensitivity analysis revealed that an increase in plant population from 100 plants to 150 plants $\mathrm{m}^{-2}$ resulted in $23 \mathrm{~kg} \mathrm{ha}^{-1}$ higher yield. A further increase in plant population to 200 plants $\mathrm{m}^{-2}$ raised it by another $20 \mathrm{~kg}$ $\mathrm{ha}^{-1}$ indicating that yield levels off after certain plant population limits. Akula (2003) carried out sensitivity of WTGROWS simulated grain yield under varying temperatures. Results showed that yield values with a temperature increase of $1^{\circ}$ and $5^{\circ} \mathrm{C}$ above the mean temperature decreased grain yields correspondingly from $5737 \mathrm{~kg} \mathrm{ha}^{-1}$ to $4583 \mathrm{~kg} \mathrm{ha}^{-1}$. The corresponding values of percentage change from the base potential yield were -9.61 to -28.50 . On the other hand, increased simulated yield with decrease in temperature ranged respectively between $6888 \mathrm{~kg} \mathrm{ha}^{-1}$ at $1^{\circ} \mathrm{C}$ decrease in temperature to $8579 \mathrm{~kg} \mathrm{ha}^{-1}$ at $5^{\circ} \mathrm{C}$, decrease in temperature.

\section{MATERIALS AND METHODS}

The CERES-wheat model was calibrated and validated with the data sets generated during rabi seasons of 20012002 and 2002-2003, through field experiment laid out in strip plot design with four replications on loamy sand soils of the Agronomy Farm, B.A. College of Agriculture, Anand Agricultural University, Anand (Gujarat, India). The main treatments were three dates of sowing with an interval of two weeks from $1^{\text {st }}$ Nov. to $30^{\text {th }}$ Nov. $\left(D_{1}-1^{\text {st }}\right.$ Nov., $D_{2}-15^{\text {th }}$ Nov. and $D_{3}-30^{\text {th }}$ Nov.) and the sub plot treatments were irrigation levels ranging between three irrigation in $\mathrm{I}_{1}$ and six irrigations in $\mathrm{I}_{4}$ coinciding with critical stages of crop growth. The sub plot details were: $\mathrm{I}_{1}-$ CRI, BT and ML, $\mathrm{I}_{2}-\mathrm{CRI}, \mathrm{TL}, \mathrm{FL}$ and DS, $\mathrm{I}_{3}-\mathrm{CRI}, \mathrm{TL}, \mathrm{BT}, \mathrm{FL}$ and $\mathrm{ML}$ and $\mathrm{I}_{4}-$ CRI, TL, BT, FL, ML and DS (CRICrown Root Initiation, TL- Tillering, BT-Booting, FL-Flowering, ML-Milking and DS- Dough Stage).

The weather parameters selected for sensitivity analysis were ambient temperature $\left( \pm 1\right.$ to $\left.\pm 5^{\circ} \mathrm{C}\right)$, solar radiation $\left( \pm 1\right.$ to $\left.\pm 5 \mathrm{MJm}^{-2} \mathrm{day}^{-1}\right)$ and concentration of carbon dioxide (1.2 and $2.4 \%$ higher concentration of $330 \mathrm{ppm}$ ), while the non-weather parameters included plant population (150 to 500 per $\mathrm{m}^{2}$ ) and sowing depth (1.5 to 7.0 $\mathrm{cm})$. The model simulated wheat grain yields under altered weather and nonweather parameters, for both (optimal condition represented by the treatment: $\mathrm{D}_{2} \mathrm{I}_{4}$ and sub-optimal condition as represented by: $\mathrm{D}_{2} \mathrm{I}_{1}$ ) have been compared with corresponding treatments for the year 2001-2002.

\section{RESULTS AND DISCUSSION}

\section{Effects of ambient temperature}

The effects of ambient temperature on simulated grain yield of wheat under optimal and sub-optimal conditions and the comparison of this simulated grain yield with base yield and its per cent change from base yield are presented in Fig. 01 to 04 and in Table 01 to 02 , respectively. 

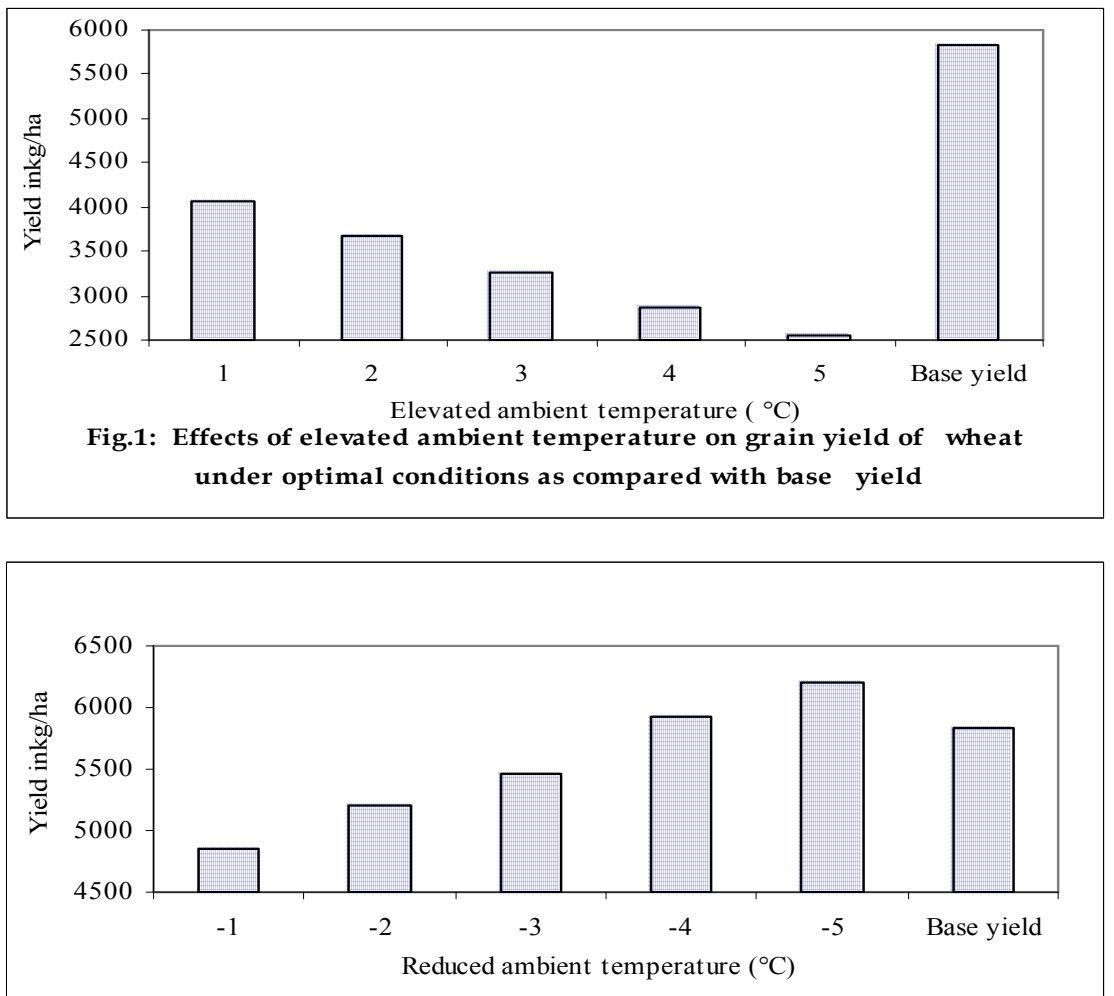

Fig.2: Effects of reduced ambient temperature on grain yield of wheat under optimal conditions as compared with base

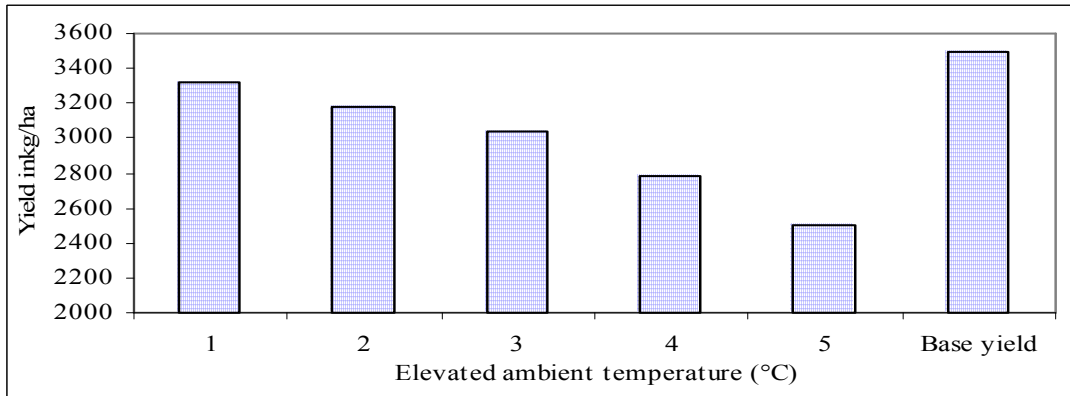

Fig. 3: Effects of elevated ambient temperature on grain yield of wheat under sub-optimal conditions as compared with base yield

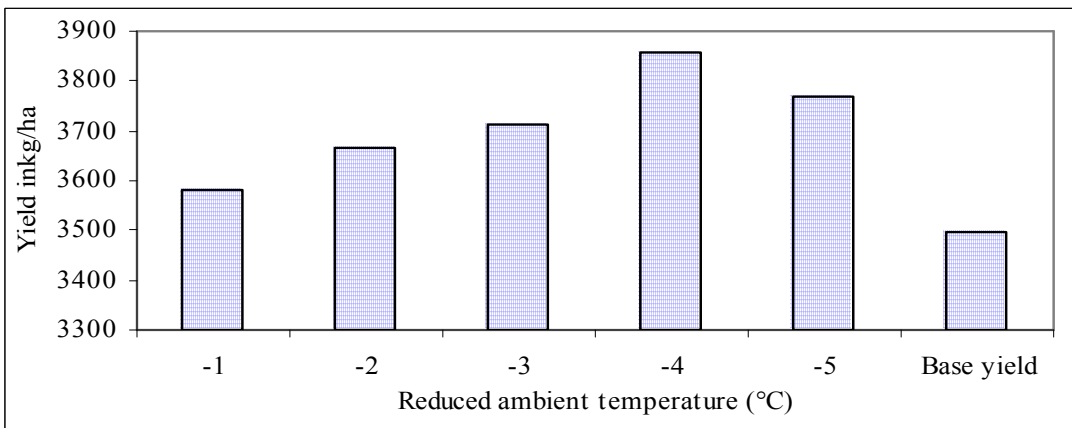

Fig. 4: Effects of reduced ambient temperature on grain yield of wheat under sub- optimal conditions as compared with base yield 
Table 01: Sensitivity of CERES-wheat model to ambient temperature under optimal condition

\begin{tabular}{ccc}
\hline $\begin{array}{c}\text { Mean ambient } \\
\text { temperature }\left({ }^{\circ} \mathrm{C}\right)\end{array}$ & $\begin{array}{c}\text { Simulated grain yield } \\
\left(\mathrm{kgha}^{-1}\right)\end{array}$ & $\begin{array}{c}\text { \% Change from base } \\
\left(5825 \mathrm{kgha}^{-1}\right) \text { yield }\end{array}$ \\
\hline 1 & 4078 & -30 \\
2 & 3675 & -37 \\
3 & 3266 & -44 \\
4 & 2866 & -51 \\
5 & 2537 & -56 \\
-1 & 4844 & -17 \\
-2 & 5198 & -11 \\
-3 & 5466 & -6 \\
-4 & 5922 & 2 \\
-5 & 6198 & 6 \\
\hline
\end{tabular}

Table 02: Sensitivity of CERES-wheat model to ambient temperature under suboptimal condition

\begin{tabular}{ccc}
\hline $\begin{array}{c}\text { Mean ambient } \\
\text { temperature }\left({ }^{\circ} \mathrm{C}\right)\end{array}$ & $\begin{array}{c}\text { Simulated grain yield } \\
\left(\mathrm{kgha}^{-1}\right)\end{array}$ & $\begin{array}{c}\text { \% Change from base } \\
\left(3499 \mathrm{kgha}^{-1}\right) \text { yield }\end{array}$ \\
\hline 1 & 3320 & -5 \\
2 & 3182 & -9 \\
3 & 3035 & -13 \\
4 & 2784 & -20 \\
5 & 2503 & -28 \\
-1 & 3580 & 2 \\
-2 & 3667 & 5 \\
-3 & 3713 & 6 \\
-4 & 3860 & 10 \\
-5 & 3770 & 8 \\
\hline
\end{tabular}

Sensitivity of CERES-Wheat model simulated grain yield to incremental units of ambient temperature showed a gradual decrease in yield ranging from 4078 to $2537 \mathrm{~kg} \mathrm{ha}^{-1}$ (Table 01). The down scaled ambient temperature increased the yield by 2 and 6 per cent at 4 and $5^{\circ} \mathrm{C}$ reduction in mean ambient temperature, respectively. The reduction in temperature from -1 to $-3^{\circ} \mathrm{C}$ also revealed an increasing yield. Such behaviour of the model was mainly due to reduction in duration of anthesis and grain filling with rise in ambient temperature and vice versa (Aggarwal and Sinha, 1993; Aggarwal and Kalra, 1994; Muchow et al., 1997). Pathak et al. (2003) also stated on the basis of sensitivity analysis of CERES-Wheat that elevated maximum temperature decreased wheat yield significantly. Akula (2003) has reported similar findings for WTGROWS and INFOCROP models for wheat (cv. GW496).

Similar results were also obtained under sub-optimal conditions (Table 02) except 


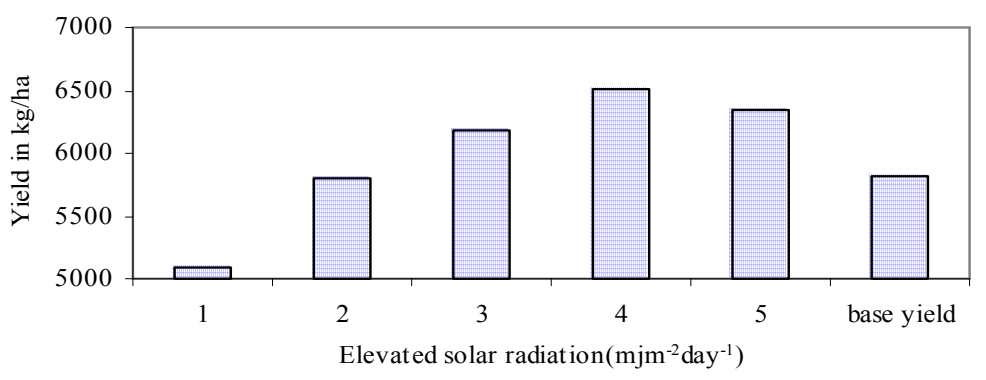

Fig. 5: Effect of elevated solar radiation on grain yield of wheat under optimal conditions as compared with base yield

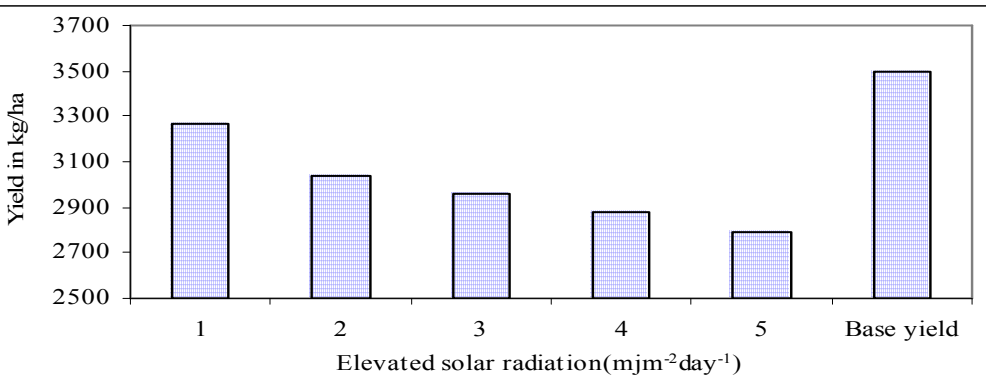

Fig. 6: Effects of elevated solar radiation on wheat grain yield under sub-optimal conditions as compared with base yield

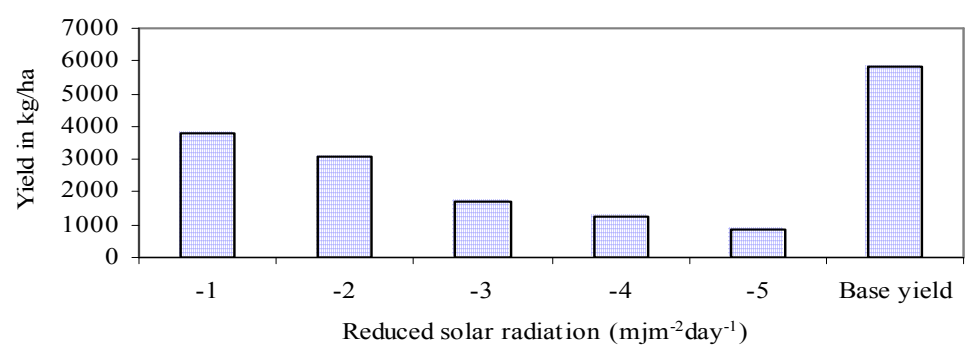

Fig. 7: Effect of reduced solar radiation on grain yield of wheat under optimal conditions as compared with base yield

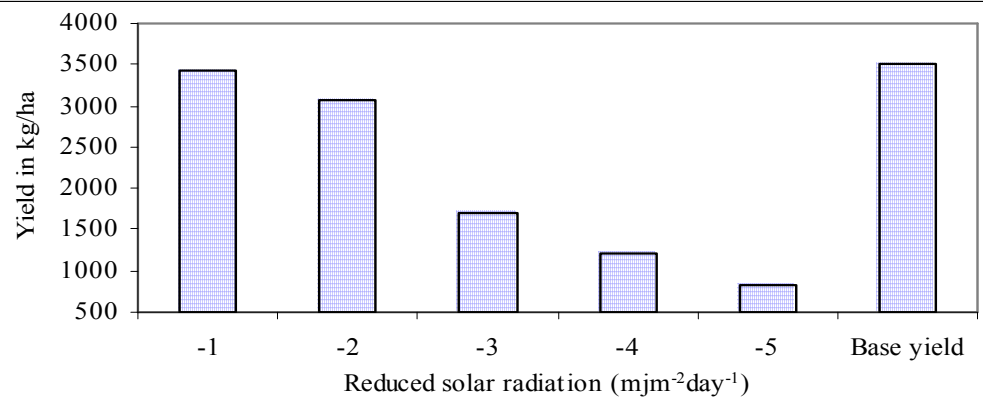

Fig. 8: Effects of reduced solar radiation under sub-optimal conditions on grain yield of wheat as compared with base yield 
for slight variation in the results of reduced ambient temperature (-1 to $\left.3^{\circ} \mathrm{C}\right)$. The percentage of decrease in yield ranged from $-5\left(3320 \mathrm{kgha}^{-1}\right)$ to $28\left(2503 \mathrm{kgha}^{-1}\right)$ corresponding to 1 and $5^{\circ} \mathrm{C}$ rise in ambient temperature while reduction in ambient temperature showed a gradual increase in yields. The percentage of change was $2\left(3580 \mathrm{kgha}^{-}\right.$ $\left.{ }^{1}\right)$ at -1 and $8\left(3770 \mathrm{kgha}^{-1}\right)$ at $-5^{\circ} \mathrm{C}$.

\section{Effects of solar radiation}

The results of varying solar radiation and its effects on wheat grain yield as simulated by CERES-Wheat model for optimal and sub-optimal situations are presented in Fig. 05 to 08 and in Table 03 to 04 , respectively.

Table 03: Sensitivity of CERES-wheat model to solar radiation under optimal condition

\begin{tabular}{ccc}
\hline $\begin{array}{c}\text { Solar radiation } \\
\left(\mathrm{MJ} \mathrm{m}^{-2} \mathrm{day}^{-1}\right)\end{array}$ & $\begin{array}{r}\text { Simulated grain yield } \\
\left(\mathrm{kgha}^{-1}\right)\end{array}$ & $\begin{array}{c}\text { \% Change from base } \\
\left(5825 \mathrm{kgha}^{-1}\right) \text { yield }\end{array}$ \\
\hline 1 & 5094 & -12 \\
2 & 5795 & -0.5 \\
3 & 6175 & 6 \\
4 & 6503 & 12 \\
5 & 6353 & 9 \\
-1 & 3785 & -35 \\
-2 & 3077 & -47 \\
-3 & 1714 & -71 \\
-4 & 1217 & -79 \\
-5 & 826 & -86 \\
\hline
\end{tabular}

Table 04: Sensitivity of CERES-wheat model to solar radiation under sub-optimal condition

\begin{tabular}{ccc}
\hline $\begin{array}{c}\text { Solar radiation } \\
\left(\mathrm{MJ} \mathrm{m}^{-2} \mathrm{day}^{-1}\right)\end{array}$ & $\begin{array}{c}\text { Simulated grain yield } \\
\left(\mathrm{kgha}^{-1}\right)\end{array}$ & $\begin{array}{c}\text { \% Change from base } \\
\left(3499 \mathrm{kgha}^{-1}\right) \text { yield }\end{array}$ \\
\hline 1 & 3265 & -7 \\
2 & 3041 & -13 \\
3 & 2962 & -15 \\
4 & 2879 & -18 \\
5 & 2787 & -20 \\
-1 & 3439 & -2 \\
-2 & 3077 & -12 \\
-3 & 1714 & -51 \\
-4 & 1217 & -65 \\
-5 & 826 & -76 \\
\hline
\end{tabular}



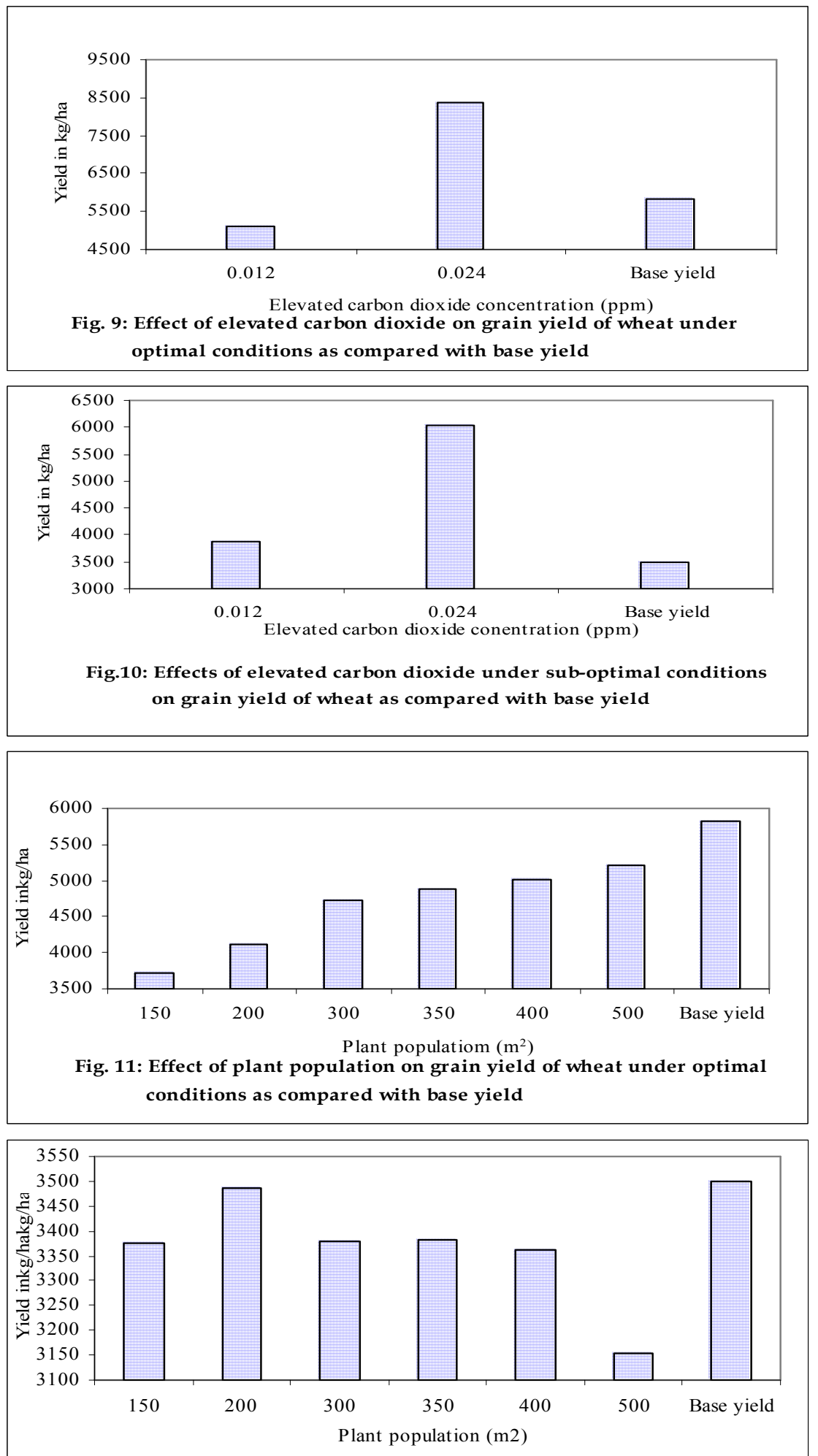

Fig. 12: Effects of plant population under sub-optimal conditions on grain yield of wheat as compared with base yield 

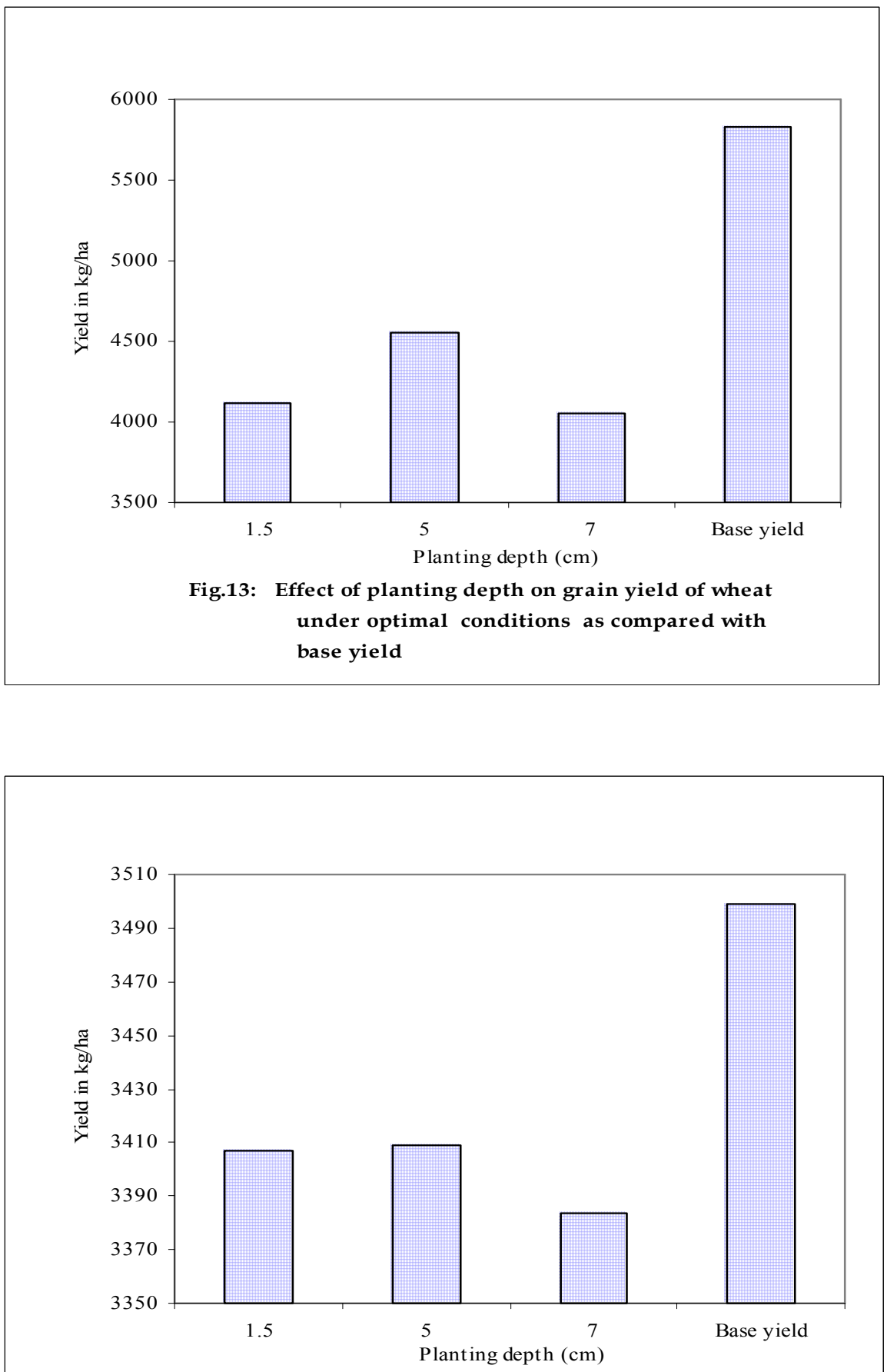

Fig. 14: Effects of planting depth under sub-optimal conditions on grain yield of wheat as compared with base yield 
Results showed that with increase from 3 to $5 \mathrm{MJm}^{-2}$ day $^{-1}$ solar radiation, percentage yield increased from 6 to 9 in comparison with base yield (Table 03). Highest yield increment was observed at $4 \mathrm{MJm}^{-2}\left(6503 \mathrm{kgha}^{-1}\right)$. In case of gradual reduction in solar radiation, gradual decrease in yield in terms of per cent change from base yield was noted as -35 to -86 for reduction in solar radiation by -1 to $-5 \mathrm{MJm}^{-2}$ day $^{-1}$, respectively. Thus, a scrutiny of the overall response of varying radiation to grain yield of wheat showed that the model was less sensitive to radiation than it was to temperature. These findings have been in conformity with the findings of Akula (2003) on use of WTGROWS and INFOCROP models for wheat cv. GW-496.

The performance of alteration in radiation under sub-optimal conditions (Table 04) both under elevated as well as reduced solar radiation revealed that the values of the percentage change from base yield failed to show any yield increment. Here also model exhibited its insensitivity to radiation regimes.

\section{Effect of elevated carbon dioxide}

The effect of elevated carbon dioxide ( 1.20 and $2.40 \%$ of the base value 330 ppm) on simulated grain yield of wheat under optimal and sub-optimal condition in relation to base yield have been depicted in Fig. 09 to 10, respectively. Fig. 9 showed that at $1.20 \%$ elevation in $\mathrm{CO}_{2}$ concentration over its base value yield decreased by 12 per cent. However, when the $\mathrm{CO}_{2}$ concentration was raised from 1.20 to $2.40 \%$, over the base value the yield increased by up to 43 per cent of the base yield under optimal condition. A yield increase of nearly 11 and 73 percent over the base yield was observed under 1.2 and 2.4 percent increase of $\mathrm{CO}_{2}$ concentration in sub-optimal conditions (Figure. 10). Lal et al. (1998) observed that a $3^{\circ} \mathrm{C}$ rise in temperature (under elevated $\mathrm{CO}_{2}$ concentration) nearly cancelled out positive effect of elevated $\mathrm{CO}_{2}$ on the wheat and rice yields as studied through use of CERES-Wheat and rice models for NW India. This clearly showed that doubled concentration of $\mathrm{CO}_{2}$ had a significant and positive impact on the grain yield of wheat. Matthews et al. (1997) found through the use of General Circulation Model in case of rice that under doubled $\mathrm{CO}_{2}$ concentration the yield increased. This showed that the model used in this study had the potential for assessing the impacts of climate change on wheat production.

\section{Effect of plant population}

The varying plant population per square meters and its impact on grain yield of wheat under optimal and sub-optimal conditions in comparison with base yield are depicted in Fig. 11 to 12, respectively. Large yield reductions were observed on increasing plant population from 150 to 500 per sq. meter and the range of per cent yield reduction as observed was -36 to -10 when compared with the base yield. In case of sub-optimal conditions (Fig. 12) the range of yield reductions was -3.5 to 9.8 for corresponding increase in plant population. This showed the strength of the model to sensitivity to varying plant population level. Shekh and Rao (1996) also obtained similar results for maize crop yields under varying planting geometry as simulated by CERES-Maize model. 


\section{CONCLUSIONS}

Response of the simulation in respect of grain yield to incremental units of ambient temperature showed gradual decrease, while the down scaled temperature increased the yield by 2 and 6 per cent at 4 and $5{ }^{\circ} \mathrm{C}$ respectively under optimal conditions in comparison with the base yield. Similar results were obtained under sub-optimal conditions except for slight variation in the pertinent values. The model was found to be less sensitive to elevated and downscaled solar radiation both under optimal and sub-optimal condition than it was to the similar changes in the temperature. Under doubled carbon dioxide concentration (660 ppm), the yield increased by up to 43 and 73 per cent respectively under optimal and suboptimal condition as compared to their respective base yields. The model was found enough sensitive to account for the effects of varying plant population both under optimal and sub-optimal condition on comparison with the simulated values of yields under these conditions with the values of base yield under respectively the same conditions.

\section{References:}

Aggarwal P.K. and N. Kalra, (1994). Analyzing the limitations set by climatic factors, genotype and water and nitrogen availability on productivity of wheat II. Climatically potential yields and management strategies. Field Crops Res. 38: 93-103.

Aggarwal P.K. and S.K.Sinha, (1993). Effect of probable increase in carbon dioxide and temperature on wheat yields in India. J. Agric. Meteorol., 48 : 811-814.

Akula B., (2003). Estimating wheat yields in Gujarat using WTGROWS and INFOCROP models. Ph.D. (Agri. Meteorology) thesis submitted to GAU, Sardar krishinagar.

Dhaliwal L., K.G.Singh, and G.S. Mahi, (1997). Dynamic simulation of wheat growth, development and yield with CERES-Wheat model. Ann. Agric. Res., 18: 157164.

Lal M., Singh K.K. Srinivasan, G. Rathore, L.S. D. Naidu and C.N.Tripathi, (1998). Growth and yield response of soybean in Madhya Pradesh, India to climate variability and change. Agric. For. Meteorol., 93 : 53-70.

Matthews R.B., M.J Kropff,. J. Horie and D.Bachelet, (1997). Simulating the impact of climate change on rice production in Asia and evaluating options for adaptation. Agric. Syst. Oxford : Elsevier Science Ltd.

Muchow R.C., C.I. Evensen, R.V. Osgood and M.J. Robertson, (1997). Yield accumulation in irrigated sugarcane. II. Utilization of intercepted radiation. Agron. J., 89: 652-656.

Pathak H., J.K. Ladha, P.K. Aggarwal, S. Peng, S.Das, Yadvinder Singh, Bijay Singh, S.K Kamara,. B.Mishra, A.S.R.A.S Sastri, H.P. Aggarwal, D.K. Das, and R.K. Gupta, (2003). Trends of climatic potential and on-farm yields of rice and wheat in the Indo-Gangetic Plains. Field Crops Res., 80: 223-234.

Shekh A.M. and B.B. Rao,(1996). Crop growth modeling: Possibilities and limitations An Indian perspective, In: Climate variability and agriculture, Abrol, Y.P.; Gadgil, S. and Pant, G.B. (Eds.). Narosa Publishing House, New Delhi, India, pp.356-376. 